\title{
Body Composition and Aerobic Fitness like a Result of 6 Months Walking Program in Senior Women
}

\author{
Václav Bunc, Pavel Hráský and Marie Skalská \\ Faculty of physical education and sports, Charles University, Prague, Czech Republic \\ Correspondence should be addressed to: Václav Bunc; bunc@ftvs.cuni.cz
}

Received Date: 23 October 2013; Accepted Date: 18 February 2014; Published Date: 27 March 2014

Academic Editor: Markku J. Alén

Copyright @ 2014 Václav Bunc, Pavel Hráský and Marie Skalská. Distributed under Creative Commons CC-BY 3.0

\begin{abstract}
The aim of this study was to verify if a moving programme based on walking may influence aerobic fitness and body composition in female seniors.

The exercise intensity ( $\min 90 \%$ of walking) at a level of 50 to $70 \% \mathrm{VO}_{2 \text { peak }}$ (HR ranged from 65 to $85 \%$ of $\left.\mathrm{HR}_{\text {peak }}\right)$ was used in a group of healthy senior women $(n=53$, age $=68.7 \pm 5.0$ years, $\mathrm{BM}=69.9 \pm 7.9 \mathrm{~kg}$, height $=161.0 \pm 2.8 \mathrm{~cm}, \% \mathrm{BF}=37.5 \pm 5.1 \%, \mathrm{VO}_{2 \text { peak }} \cdot \mathrm{kg}^{-1}=25.9 \pm 4.3 \mathrm{ml} \cdot \mathrm{kg}^{-1} \cdot \mathrm{min}^{-1}$ ). Control group were senior women without any regular physical activity $(26,68.9 \pm 4.8 y e a r s$, $70.3 \pm 8.1 \mathrm{~kg}, 160.3 \pm 2.0 \mathrm{~cm}, 38.4 \pm 5.7 \%, 24.2 \pm 3.4 \mathrm{ml}_{\mathrm{kg}}{ }^{-1} \cdot \mathrm{min}^{-1}$ ). Exercise time ranged between $90-250 \mathrm{~min}$ per week $(156.8 \pm 48.9 \mathrm{~min})$. Walking time ranged between $82-233 \mathrm{~min}$ $(142.8 \pm 45.7 \mathrm{~min})$. The energy output was in range from $2675 \mathrm{~kJ}$ to $7740 \mathrm{~kJ}(3970 \pm 960 \mathrm{~kJ})$ per week. After 6 months of training BM increased $(0.8 \pm 1.7 \mathrm{~kg}$; NS), \%BF decreased $(0.6 \pm 1.5 \%$; $\mathrm{NS})$, and $\mathrm{BCM}$ increased $(10.0 \pm 2.3 \% ; \mathrm{p}<0.01)$. $\mathrm{VO}_{2 \text { peak }}$ increased by $8.0 \pm 3.3 \%$; $(\mathrm{p}<0.01)$. Similarly, the maximum speed of running increased by $7.8 \pm 1.5 \%$; $(p<0.01)$ compared to the baseline measurements. In non-active group we did not found any significant changes in all followed variables in the same time period. We may conclude that a 6-month exercise program based on continuous walking that produced an energy expenditure of $3970 \mathrm{~kJ}$ during a week, is useful for the improvement of AF and BC in senior women.
\end{abstract}

Keywords: Body composition, senior women, aerobic fitness, treadmill testing.

\section{Introduction}

The health benefits of physical activity are well documented in relation to body mass management and the prevention of chronic illnesses, as well as improving mental health and cognitive function (Ogilvie et al. 2007). However, our knowledge of the benefits of physical activity is not matched by our understanding of how to get people active and maintain activity (Kroeze, Werkman, Brug 2006, Marques et al. 2014).

There is a need for developing and trialing strategies for older people (65 years and above) to include physical activity into their lifestyle." These interventions need to be systematic, robust, and longer-term, incorporating different methods of 
engaging this population (Eakin et al. 2007, Kroeze, Werkman, Brug 2006).

Regular participation at recommended levels of physical activity can minimize physiologic changes associated with aging, increase longevity, and decrease the risk of many diseases (Marques et al. 2014, Rikli \&Jones 2013, WHO 2004).

Age related changes in body composition (BC) have implications for physical function and health. A redistribution of and an increase in fat and a loss of muscle mass may result in a substantial decrease in the functional capacity. Although the BC, as well as age-related changes in it, has a strong genetic component, it is also significantly affected by environmental factors. The primary influences are nutrition, disease, and mainly physical activity (Spirduso 1995).

Clinically, the most used BC model describes the human body mass (BM) as a sum of the fat mass (FM) and the fat-free body mass (FFM) components (Blanchard et al.1990). In a majority of cases, this model could be accepted, but for more detailed characterizing of movement predispositions, it is better to use the 3-C molecular model that may be described in the following form (Heyward and Wagner 2004):

$$
\begin{aligned}
& \mathrm{BM}=\mathrm{FM}+\mathrm{FFM}=\mathrm{FM}+\mathrm{ECS}+\mathrm{ECF}+\mathrm{BCM} \\
& \mathrm{FFM}=\mathrm{ECS}+\mathrm{ECF}+\mathrm{BCM} \\
& \mathrm{FFM}=\mathrm{ECM}+\mathrm{BCM}
\end{aligned}
$$

$\mathrm{ECS}=$ extracellular solids, $\mathrm{ECF}=$ extracellular fluids, and BCM = body cell mass

Because FFM is depends on BCM, this is often used to characterize the relationship ECM/BCM. Generally, it is well recognized that lower ECM/BCM value correspond to a better predispositions for exercise (Bunc et al. 2000).

Beginning in the middle of adulthood, FFM begins to decline gradually both in men and women, primarily due to the loss of muscle tissue (Blanchard et al. 1990). Similarly to FFM, the body cell mass (BCM) decreases with age in subjects without any systematical physical training, and thus significantly changes the predispositions for exercise. This similarity is confirmed by a highly significant positive correlation between these two variables that was found in senior women (Bunc et al. 2000). The BCM is a sum of oxygen-using, calciumrich, glucose-oxidising cells and is recognized as an indirect measure of the ability of a person to sustain mechanical work (Bunc et al. 2000).

Numerous tools and methodologies have been developed to measure various $\mathrm{BC}$ parameters. The bioelectrical impedance analysis (BIA) seems to be one of the most used methods in field settings (Heyward and Wagner 2004, Roche et al. 1996). Regardless of which instrument is chosen to assess BC, the method is only as good as the measurement technique and prediction or conversion formula applied. To remain valid, the conversion formulas and prediction equations selected must be restricted to the populations from which they were derived (Bunc et al. 2000, Heyward and Wagner 2004, Roche et al. 1996).

One of the most studied topics in exercise research has focused on the effect of exercise on the influence of actual state of subjects, on improvement of health and work capacity predispositions in cardiovascular predispositions, mainly assessed by measuring of maximal or peak oxygen uptake $\left(\mathrm{VO}_{2 \text { peak }}\right)$ (Astrand and Rodahl 1986, Blair and Connelly 1996, Bunc 1999, Heyward 2010, Marques et al. 2014, Seguin and Nelson 2003). Physical fitness it is not only the predisposition of physical performance, but must be clear what specific types of fitness, including both morphological (muscle mass, body composition) and functional parts (strength, flexibility, balance) may influence the actual human performance (Blair and Connelly 1996, Heyward 2010). In seniors, the actual physical fitness state is not only the predisposition of a better physical performance but it is the 
significant basis of their independency (Bunc et al. 2000, Kostic et al. 2011).

When we assess the influence of physical activity on actual state of human, it is important to know its energy requirement (Bunc 1994). A significant influence of human state is exerted only by the physical exercises, their energy content during an application of which a certain minimal threshold exceeded. The level depends on the goal of intervention for which these activities are performed, and on the actual subject's fitness level (Bunc 1999).

The aim of this study was to assess the effects of an exercise program based exclusively on walking - on aerobic fitness described by peak oxygen uptake and changes in BC in healthy senior women.

\section{Material and Methods}

Two groups of non-trained healthy senior women (53 and 26) were included in this study. The research was performed in groups of seniors (subjects older then 65 years residing in the area of Prague, without any objective internal limitation) that took part in physical activity programs of the Faculty of Physical Education and Sports of Charles University in Prague, and in exercising senior groups of Sokol in Prague (53 senior women) and senior women (26) without of regular physical exercise from the same locality. Active seniors were chosen by random selection from a group of two hundred trainees and inactive seniors from a group of three hundred applicants from the locality Prague.

Before the start of their participation in this study, all the seniors underwent a medical evaluation together with cycle ergometer testing and dynamical ECG and blood pressure assessment that were accomplished by a physician one week before the start of the program and were informed about the consent of intervention.

Selected anthropometrical and maximum functional variables are reported in Table 1.

Table 1: Means $\pm S_{d}$ of Selected Anthropometrical and Functional Variables in Physically Active Active) and Non Active (Non Active) Senior Women before and after 6 Months of Exercise Program in Active and before and after 6 Months of Normal Daily Movement Regime

\begin{tabular}{|l|l|l|ll|}
\hline & $\begin{array}{l}\text { Active } \\
\text { Before - 1 }\end{array}$ & $\begin{array}{l}\text { Active } \\
\text { After - 2 }\end{array}$ & $\begin{array}{l}\text { Non active } \\
\text { Before }-3\end{array}$ & $\begin{array}{l}\text { Non active } \\
\text { After - 4 }\end{array}$ \\
\hline $\mathrm{N}$ & 53 & 53 & 26 & 26 \\
\hline Age (years) & $68.7 \pm 5.0$ & $69.2 \pm 5.0$ & $68.9 \pm 4.8$ & $69.4 \pm 4.8$ \\
\hline Body mass $(\mathrm{kg})$ & $69.9 \pm 7.9$ & $70.4 \pm 7.8$ & $70.3 \pm 8.1$ & $70.2 \pm 8.0$ \\
\hline Height $(\mathrm{cm})$ & $161.0 \pm 2.8$ & $160.8 \pm 2.9$ & $160.3 \pm 2.0$ & $160.2 \pm 2.1$ \\
\hline$\%$ BF $(\%)$ & $37.5 \pm 5.1$ & $36.9 \pm 4.8$ & $38.4 \pm 5,7$ & $38.6 \pm 5.7$ \\
\hline FFM $(\mathrm{kg})$ & $43.7 \pm 6.8$ & $45.9 \pm 6.7$ & $43.3 \pm 6.9$ & $43.1 \pm 7.1$ \\
\hline ECM/BCM & $0.98 \pm 0.03$ & $0.88 \pm 0.02$ & $1.01 \pm 0,06$ & $1.02 \pm 0.06$ \\
\hline Speed $_{\text {peak }}\left(\mathrm{km} \cdot \mathrm{h}^{-1}\right)$ & $6.0 \pm 1.1$ & $6.5 \pm 0.9$ & $5.6 \pm 0.4$ & $5.7 \pm 0.6$ \\
\hline $\mathrm{VO}_{\text {2peak }} \cdot \mathrm{kg}^{-1}(\mathrm{ml})$ & $25.9 \pm 4.3$ & $28.0 \pm 4.0$ & $24.2 \pm 3.4$ & $24.4 \pm 3.6$ \\
\hline
\end{tabular}

The body cell mass was calculated using FFM and the phase angle $\alpha$ between whole impedance vector and resistance (Bunc et al. 2000, Heyward and Wagner 2004). The extra cellular mass (ECM) is the difference between FFM and BCM (ECM = FFM BCM). The FFM was calculated according to the modified formula of Deurenberg and Schouten (1992).
The resistance and reactance were measured at four frequencies - 1, 5, 50 and $100 \mathrm{kHz}$ (B.I.A. 2000M, Data Input, Germany) on the right side of the body by a tetrapolar electrode configuration in accordance with manufacturer's specification. 
The physical performance was tested under field testing conditions by a walking test - $1600 \mathrm{~m}$ walk on a flat terrain, mainly on the track. The test was carried out within the time range of one week before and one week after laboratory evaluation. The basic instruction was "try to go the whole distance with maximal effort". During this walk the HR was monitored by Sporttester Polar.

The maximum functional variables were determined on a treadmill with a slope of $5 \%$ during a progressive walking test until subjective exhaustion. The initial speed on the treadmill was $3 \mathrm{~km} \cdot \mathrm{h}^{-1}$, and was increased each minute by $1 \mathrm{~km} \cdot \mathrm{h}^{-1}$. The cardiorespiratory variables were measured in an open system using an online method by TEEM 100 (Aerosport). All analyzers were checked before and after each test by calibration gas of known concentration. The ventilation was controlled before and after test by a mechanical pump.

In active groups the energy demand of physical exercise was measured by a Caltrac monitor, and simultaneously by an assessment of energy cost during the exercise from the general relationship between the exercise intensity and the energy that a person needs to cover the activity (Bunc 1994). The differences between both methods were lower than $12 \%$.

According to our measurements in senior women $(n=106$, mean age $70.3 \pm 2.7$ year), the general dependence of oxygen consumption on walking speed on flat surface, temperature about $20^{0}$ of Celsius, humidity about $70 \%$ in a range of intensities of 3-7 km.h-1 was established in the form

$\mathrm{VO}_{2} \cdot \mathrm{kg}^{-1}\left(\mathrm{ml} \cdot \mathrm{kg}^{-1} \cdot \mathrm{min}^{-1}\right)=5.3488^{*} \mathrm{v}\left(\mathrm{km} \cdot \mathrm{h}^{-1}\right)$ $-6.0561$

$\mathrm{r}=0.872, \mathrm{p}<0.005, \mathrm{~S}_{\mathrm{EE}}=1.49 \mathrm{ml} \cdot \mathrm{kg}^{-1} \cdot \mathrm{min}^{-1}$, $\mathrm{T}_{\mathrm{EE}}=1.74 \mathrm{ml} \cdot \mathrm{kg}^{-1} \cdot \mathrm{min}^{-1}$

For the calculation of energy cost from oxygen uptake, mean energy equivalent for oxygen of $4.83 \mathrm{kcal} . \mathrm{min}^{-1}{ }^{-1}(20.2 \mathrm{~kJ}$. min.l-1) was used, neglecting the anaerobic contribution (about 10\%) to the total metabolism (Astrand and Rodahl 1986).

The duration of an exercise session ranged from 20 to $50 \mathrm{~min}$, and exercise training was performed 3-5 times a week during 6 months. The actual realization of exercise was checked from each subject after the consultation with us. We tried to accept the individual experiences with physical activities but the walking must be minimally $85 \%$ of whole realized physical activities.

The intensity of exercise (the \% of maximal effort was described with help of heart rate) was monitored continuously by Polar Sporttester and/or by measuring the speed of walking.

The non-active group had a "normal" movement regime without regular physical exercise.

Diet in both groups was controlled by questionnaire three times during a intervention period and was practically non-changed during the whole period of evaluation.

The data of the exercise qualitative content were collected by a questionnaire.

The means and standard deviations were calculated according to standard methods. The paired t-test was used to evaluate differences between the means where appropriate. The level of significance of $\mathrm{p}<0.05$ was used. The substantive significance was in the oxygen consumption $1.5 \mathrm{ml} . \mathrm{kg}^{-1} . \mathrm{min}^{-1}$, in FFM $0.5 \mathrm{~kg}$ and in ECM/BCM coefficient 0.03 .

The limits of the study should be the number of evaluated women seniors and location of Prague.

\section{Results}

Selected anthropometrical and functional variables before and after the exercise program collected in the group of 53 nontrained healthy senior women are presented in Table 1. In the same Table are 
data from non-active women that were followed in the same time period.

In non-active group we did not found any significant changes in all followed variables.

The energy output on the level of $900 \mathrm{kcal}$ (3762 kJ) per week was observed using individually composed moving programs (Stewart et al. 2001). The moving programs consisted of continuous aerobic walking (minimally $90 \%$ of entire physical activities) at the level of 50 to $70 \% \mathrm{VO}_{2 \text { peak }}$ (HR ranged from 65 to $85 \%$ of $\mathrm{HR}_{\text {peak, }}$ or 100-140 beats.min-1). The rest of the exercise carried out was individually dependent, with a majority of home gymnastics or swimming. This activity should have been quantified to exclude it's major effects on your results.

After a 6-month training program, a slightly non-significant body mass increase $(0.5 \pm 1.2 \mathrm{~kg})$, and body fat decrease $(0.6 \pm 1.4 \%)$ were found. A significant increase in fat free mass $(2.0 \pm 1.5 \mathrm{~kg}$; $5.0 \pm 1.7 \%$; $\mathrm{p}<0.05$ ) was found, and it was detected also in BCM $(2.3 \pm 0.6 \mathrm{~kg} ; 10.0 \pm 2.3$ $\% ; \mathrm{p}<0.01$ of the initial value). The peak oxygen uptake increased significantly by $2.1 \pm 1.2 \mathrm{ml} . \mathrm{kg}^{-1} \cdot \mathrm{min}^{-1} ; 8.0 \pm 3.3 \%$; $<0.01$ of initial value. Similarly as in maximum oxygen uptake, the maximum speed of treadmill walking increased significantly by $0.5 \pm 0.3 \mathrm{~km} . \mathrm{h}^{-1} ; 7.8 \pm 1.5 \%$; $<0.01$ of initial value.

A highly significant dependence of peak oxygen uptake on ECM/BCM was found

$\mathrm{VO}_{2 \text { peak }} \cdot \mathrm{kg}^{-1} \quad\left(\mathrm{ml} \cdot \mathrm{kg}^{-1} \cdot \mathrm{min}^{-1}\right) \quad=\quad-$ 43.165*ECM $/ \mathrm{BCM}+67.765$

$\mathrm{r}=0.911, \mathrm{p}<0.005, \mathrm{~S}_{\mathrm{EE}}=1.68 \mathrm{ml} \cdot \mathrm{kg}^{-1} \cdot \mathrm{min}^{-1}$, $\mathrm{T}_{\mathrm{EE}}=1.93 \mathrm{ml} \cdot \mathrm{kg}^{-1} \cdot \mathrm{min}^{-1}$
The ratio ECM/BCM increased significantly with the age. The following linear dependence was established:

$\mathrm{ECM} / \mathrm{BCM}=0.021 *$ age $($ years $)+0.412$

$\mathrm{r}=0.898, \mathrm{p}<0.005, \mathrm{~S}_{\mathrm{EE}}=0.04, \mathrm{~T}_{\mathrm{EE}}=0.05$

The time spent at the described exercise intensity per week ranged between 90-250 min (mean 156.8 $\pm 48.9 \mathrm{~min}$ ). Walking time ranged between 82 and 233 min (mean $142.8 \pm 45.7 \mathrm{~min})$. In the relative description of the total exercise time, this was estimated as $90.0 \%$ - 93.2\%. The time spent by other forms of physical activities ranged between 8 and $27 \mathrm{~min}$, in the relative description it was in a range from 11.8 to $13 \%$ of the total exercise time. The rest of exercise was carried out as home gymnastics, swimming, jogging or cycling. According to data from non active group the influence of the resting activities should be neglected.

The energy output of accomplished moving activities ranged from $650 \mathrm{kcal}(2675 \mathrm{~kJ})$ to $1780 \mathrm{kcal}(7740 \mathrm{~kJ})$ (mean 950 $230 \mathrm{kcal}$ $3970 \pm 960 \mathrm{~kJ})$.

Performance measured as the time to complete $1600 \mathrm{~m}$ on track, significantly increased after the 6 month program (from $1047 \pm 31 \mathrm{~s}$ to $965 \pm 42 \mathrm{~s}(\mathrm{p}<0.01)$ ). The results of $2^{\text {nd }}$ evaluation were $7.8 \pm 2.5$ $\%$ better than those of $1^{\text {st }}$ testing.

The subjects did not experience any health or serious fatigue symptoms that would limit their walking during the test. The majority of subjects, over $90 \%$ reported no symptoms. Among the most frequently reported symptoms was a pain in lower limbs. 
Table 2: Statistical Significancy of Selected Anthropometrical and Functional Variables Assessed with Help of Paired and Non-Paired T-Test in Followed Groups of Senior Women

\begin{tabular}{|l|l|l|l|l|l|l|}
\hline & $1-2$ & $1-3$ & $1-4$ & $2-3$ & $2-4$ & $3-4$ \\
\hline Age (years) & -- & -- & -- & -- & -- & -- \\
\hline Body mass (kg) & -- & -- & -- & -- & -- & -- \\
\hline Height (cm) & -- & -- & -- & -- & -- & -- \\
\hline$\%$ BF (\%) & $*$ & -- & -- & $*$ & $*$ & -- \\
\hline FFM (kg) & $*$ & -- & -- & $*$ & $*$ & -- \\
\hline ECM/BCM & $* *$ & -- & -- & $* *$ & $* *$ & -- \\
\hline Speed $_{\text {peak }}\left(\mathrm{km}^{-1}\right)$ & $* *$ & -- & -- & $* *$ & $* *$ & -- \\
\hline $\mathrm{VO}_{2 \text { peak. }} \cdot \mathrm{kg}^{-1}(\mathrm{ml})$ & $* *$ & -- & -- & $* *$ & $* *$ & -- \\
\hline
\end{tabular}

\section{Discussion}

The importance of physical activity as an element of healthy living for older adults has been widely addressed in the literature (e.g., CDCP 2005, Spirduso 1995, Rikli \& Jones 2013). Physically active older adults can reduce or prevent functional declines linked to aging through improved cardiovascular functioning, reduced risk of osteoporosis, reduced risk of falling, and reduced loss of muscle mass and strength (Goggin and Morrow 2001, Marques et al. 2014). Surveys such as the Behavioral Risk Factor Surveillance System (CDCP 2005), however, show that only one third of people age 65 years and older participate in regular sustained physical activity, defined as $30+$ min of moderate physical activity five or more days per week or vigorous physical activity for 20 min three or more days per week.

Therefore, ways older adults can modify their behaviors or leisure lifestyles to be more active are critical to promoting their health and independence, preventing or delaying illness and disability, and supporting a better quality of life. Modifying lifestyles, however, includes more than just changing individual health behaviors.

An important physiological concept of exercise in rehabilitation and/or conditioning is the type of work that the body is performing. Cyclic endurance activities such as running, walking, swimming and cycling requires movements of large muscle masses, a high blood flow, and increased cardiac output. From these activities, walking is probably the most easily accessible, and often underestimated way for increasing one's overall level of fitness and/or for moving rehabilitation in non-trained persons or in selected groups of patients. One's adaptation to walking is the highest out of all forms of physical exercise that may be used for these goals. The reason is that the walking is the basic form of subject's daily activities that are use for cover of his or her demands.

The supplementary activities like a home gymnastics, swimming etc. was altered during the evaluated period, and we found the period without of supplementary exercise (senior women only realize walking), and the presented data were not influent.

The initial values of $\mathrm{BC}$ and aerobic fitness were slightly better than those of the Czech population standards of that age. After a 6month aerobic training, the values of aerobic fitness were significantly better than our population standards, and there better than the data from our group senior women without of regular exercise (Bunc 1994, Baker et al. 2009), and the values of BC improved non-significantly. Unfortunately, we have not got comparable BCM and ECM data of the Czech senior population, nor those from other European countries. As far as we are aware, such data are not available in literature. 
Beginning in the middle of adulthood, FFM begins to decline gradually both in men and women, primarily due to wasting of muscle tissue. FFM is significantly lower in elderly women than in younger women (Blanchard et al. 1990), and it is estimated that FFM decreases on average $3 \mathrm{~kg}$ per decade in middle-aged to elderly sedentary healthy adults (Forbes \& Reina 1970). This loss is almost $1 \frac{1}{2}$ times as great in men than in women, because men were found to lose FFM at the rate of 0.34 kg.year ${ }^{-1}$, whereas women lost FFM at the rate of 0.22 kg.year1 (Forbes 1976). Between 40th and 80 th years of age, men lose FFM at the rate of $5 \%$ each decade, whereas women lose about 2.5\% FFM each decade (Rudman et al. 1991). At these rates, men and women lose approximately $20 \%$ and $10 \%$ of total FFM, respectively, between the ages of 40 and 80. Thus, while fat mass is increasing with age, FFM is decreasing (Karasik et al. 2005).

The factor that is most important for a physical independence of seniors is muscle strength (Spirduso 1995). Muscle strength is strongly dependent on muscle mass that is necessary condition for realization of exercise. This is very important in seniors, where it should be the main reason of their dependency (Seguin and Nelson 2003). It is documented that the decline of muscle strength with age has been quantified as about $15 \%$ per decade after the age of 60 (Vandervoort and McComas 1986). From a limited research that has been done in elderly women, a positive relation seems to be between the activity level and muscle strength (e.g. Rantanen et al. 1993). The form of physical training (strength or endurance) plays a decisive role for the level of muscle mass, and thus of muscle strength. Seguin and Nelson (2003) reported superior muscle performance among elderly strength-trained athletes when compared with endurance athletes or age-matched untrained controls.

In a group of 32 subjects (5 men, 27 women; mean age $66.19+/-6.92$ years; mean height, $155+/-7 \mathrm{~cm}$ ) residing in four communities in Latium and attending a senior centre took part in a 10-week exercise program conducted in twice weekly sessions of about one hour each found Faina et al. (2008) similar significant improvement in body composition, with a significant reduction in body weight and body-mass index $(\mathrm{p}<0.01)$, improved physical functional capacity, with a significant increase muscle strength $(\mathrm{p}<$ 0.01 ), joint flexibility ( $p<0.01$ ), speed of movement $(\mathrm{p}<0.01)$.

Based on theoretical background the ECM/BCM coefficient was used firstly to identify subject's fluid imbalance or malnutrition. According to new data this coefficient may be used more for assess a predisposition for muscular work in healthy or unhealthy subjects and/or in athletes. The term malnutrition refers to a loss of structural body components, which may be most accurately reflected by BCM and by an increase in ECM (Bunc et al. 2000, Roche et al. 1996).

Peak oxygen consumption values are dependent on the quality and quantity of muscle mass that contributes to securing the movement performance. Quality muscle mass can be indirectly described by the coefficient of ECM/BCM (Bunc et al. 2000). We are also found close relationship between peak consumption and ECM/BCM coefficient. In general, the relationship between $\mathrm{VO}_{2 \text { peak }}$ and intensity of movement may be described by linear dependence in the range of $20-80 \%$ in untrained and 20 $90 \%$ of maximal movement intensity in trained subjects (Bunc 1994). Generally, this relationship depends on training state - fitness state, sex, age, and previous movement experience (eg. Astrand and Rodahl 1986).

In our group of seniors we found a close relationship between the ECM/BCM and $\mathrm{VO}_{2 \text { peak }}(\mathrm{r}=0.732, \mathrm{p}<0.01) \quad$ (Bunc et al. 2000 ). In practice this means that if the effect criterion of the movement intervention the value of $\mathrm{VO}_{2 \text { peak }}$ is often used. From this follows that for the same purposes may be used the ECM/BCM coefficient.

The ECM/BCM is significantly dependent on the age of assessed subjects. This dependence may be used for actual 
development state assessment and thus for evaluation of subject's biological age (Bunc et al. 2000).

The level of ECM/BCM strongly depend on subject's age (Bunc et al. 2000). In subjects of middle age without of regularly physical training, ECM/BCM coefficients are recorded between 0.75 and 1.00 (Bunc et al. 2000).

Changes in the values of ECM/BCM coefficient can provide us with information about quantitative and qualitative changes in muscle mass. The shift towards higher values may be caused either by destruction of muscle mass, especially BCM (catabolism) or expansion of body fluids into the intracellular space (edema). In the case of dehydration found conversely shift towards lower values of ECM/BCM coefficient (Roche et al. 1996).

Since the diet of the monitored subjects was practically without any significant alterations during the whole 6 months, the significant increase in both FFM and BCM might be probably caused by the training program applied.

The changes in $\mathrm{VO}_{2 \text { peak }}$ induced by the endurance walking program are practically consistent with those found by Vitiello et al. (1997), who described a $14 \%$ increase in aerobic fitness, a significant increase in FFM, and a significant decrease in BF and total body mass in a group of senior men and women of a similar age. These results were confirmed by our data, although the changes in $\mathrm{BC}$ were not so high. The reason could be a participation of both sexes in the study of Vitiello et al. (1997).

There is evidence that the magnitude of the increase in $\mathrm{VO}_{2 \text { peak }}$ is dependent on the amount of exercise realized during a time unit (day or week) or on total energy expenditure during the imposed exercise (Bunc 1994, Baker et al. 2009). According to the results of previous studies, $\mathrm{VO}_{2 \text { peak }}$ measured either in laboratory or in the field has generally improved during the first months of conscription among nontrained subjects (Blair and Connelly 1996).
The minimum training energy expenditure required to maintain an elevated $\mathrm{VO}_{2 \text { peak }}$ has not been clearly established. For example, the most recent ACSM prescription guidelines (2013) have recommended in seniors a minimum energy expenditure of $300 \mathrm{kcal}$ per an exercise session performed four days a week, or $200 \mathrm{kcal}$ per exercise session performed five days a week.

An adequate energy output has its effect both under a presence and under an absence of other influences, and the beneficial relationship goes on with an advancing age.

In conclusion, physical training under energy expenditure higher than $900 \mathrm{kcal}$ per week accomplished with help of activities that the subjects are highly adapted to, as walking, may significantly improve the peak oxygen uptake - the aerobic fitness, and the motor performance (speed of walking) in non-trained senioraged women.

The study was supported by grant of Czech Ministry of Education MSM 0021620867 and grant of Charles University P38.

\section{References}

ACSM (2013). ACSM's Guidelines for Exercise Testing and Prescription, Baltimore, Williams and Wilkins, USA.

Astrand, P. O. \& Rodahl, K. (1986). 'Textbook of Work Physiology,' New York, Mcgraw Hill, USA.

Baker, J., Meisner, B. A., Logan, A. J., Kungl, A.- M. \& Weir, P. (2009). "Physical Activity and Successful Aging in Canadian Older Adults," Journal of Aging and Physical Activity, 17 (2) 223-235.

Blair, S. N. \& Connelly, J. C. (1996). "How Much Physical Activity Should We Do? The Case for Moderate Amounts and Intensities of Physical Activity," Research Quarterly for Exercise and Sport, 67 (2) 193-205.

Blanchard, J., Conrad, K. A. \& Harrison, G. G. (1990). "Comparison of Methods for 
Estimating Body Composition in Young and Elderly Women," Journal of Gerontology, 45 B119-B24.

Bunc, V. (1994). "A Simple Method for Estimating Aerobic Fitness," Ergonomics, 37(1): 159-65.

Bunc, V. (1999). 'Biocybernetic Approach to Evaluation of Organism Response to Physical Load,' Prague, Charles University, CZ.

Bunc, V., Štilec, M., Moravcová, J. \& Matouš, M. (2000). 'Body Composition Determination by Whole Body Bioimpedance Measurement in Women Seniors,' Acta Univ Carol Kinathropologica, 36 (1) 23-38.

CDCP. (2005). 'Behavioral Risk Factor Surveillance System Survey Data. Atlanta, GA, U.S. Department of Health and Human Services,' Centers For Disease Control And Prevention, USA.

Deurenberg, P. \& Schouten, F. J. M. (1992). "Loss of Total Body Water and Extracellular Water Assessed by Multifrequency Impedance," European Journal of Clinical Nutrition, 4 247-55.

Eakin, E. G., Lawler, S. P., Vandelanotte, C. \& Owen, N. (2007). "Telephone Interventions for Physical Activity and Dietary Behavior Change," American Journal of Preventive Medicine, 32 419-34.

Faina, M., Mirri, G., Manili, U., Cavalazzi, E., Morandini, C., Besi, M., Bali, F. \& Manno, R. (2008). 'Physiological and Psychological Effects of Physical Exercise on a Group of Elderly Non-Exercises,' Med Del Sport, 61 (2) 121-138.

Forbes, G. B. (1976). "The Adult Decline in Lean Body Mass," Human Biology, 48 16173.

Forbes, G. B. \& Reina, J. C. (1970). "Adult Lean Body Mass Declines With Age: Some Longitudinal Observation," Metabolism, 19 653-63.
Goggin, N. L. \& Morrow, J. R. Jr. (2001). 'Physical Activity Behaviors of Older Adults,' JAPA, 9 58-66.

Heyward, V. H. (2010). Advanced Fitness Assessment and Exercise Prescription, Champaign, IL, Human Kinetics, USA.

Heyward, V. H. \& Wagner, D. R. (2004). Applied Body Composition Assessment, Champaign, IL, Human Kinetics, USA.

Karasik, D., Demissie, S., Cupples, L. A. \& Kiel, D. P. (2005). "Disentangling the Genetic Determinants of Human Aging: Biological Age as an Alternative to the Use of Survival Measures," The Journals of Gerontology, 60 (5) 574-87.

Klintgaard, H., Mantoni, M. \& Schiaffino, S. (1990). "Function, Morphology and Protein Expression of Ageing Skeletal Muscle: A Cross-Sectional Study of Elderly Men with Different Background," Acta Physiol Scand, 140 41-54.

Kostic, R., Uzunovic, S., Pantelic, S. \& Duraskovic, R. (2011). "A Comparative Analysis of the Indicators of the Functional Fitness of the Elderly," Facta Universitatis, 9 (2) 161-171.

Kroeze, W., Werkman, A. \& Brug, J. (2006). "A Systematic Review of Randomized Trials on the Effectiveness of Computer Tailored Education on Physical Activity and Dietary Behavior," Annals of Behavioral Medicine, 31 205-23.

Marques, E. A., Baptista, F., Santos, R., Vale, S., Santos, D. A., Silva, A. M., Mota, J. \& Sardinha, L. B. (2014). "Normative Functional Fitness Standards and Trends of Portuguese Older Aduits: Cross-Cultural Comparisons," Journal of Aging and Physical Activity, 22 126-137.

Ogilvie, D., Foster, C. E., Rothnie, H., et al. (2007). "Interventions to Promote Walking: Systematic Review," BMJ, 334 1204-51. 
Rantanen, T., Sipila, S. \& Suominen, H. (1993). "Muscle Strength and History of Heavy Manual Work among Elderly Trained Women and Randomly Chosen Sample Population," European Journal of Applied Physiology and Occupational Physiology, 66 514-7.

Rikli, R. E. \& Jones, C. J. (2013). "Development and Validation of CriterionReferenced Clinically Relevant Fitness Standards for Maintaining Physical Independence in Later Years," The Gerontologist, 53 (2) 255-267.

Roche, A. F., Heymsfield, S. B. \& Lohman, T. G. (1996). Human Body Composition, Champaign, IL, Human Kinetics, USA.

Rudman, D., Feller, A. G., Cohn, L., Shetty, K. R., Rudman, I. W. \& Draper, M. W. (1991). "Effects of Human Growth Hormone on Body Composition in Elderly Men," Hormone Research, 36 (Suppl.1) 73-81.

Seguin, R. \& Nelson, M. E. (2003). "The Benefits of Strength Training for Older Adults," American Journal of Preventive Medicine, 25 141-9.

Spirduso, W. W. (1995). Physical Dimensions of Aging, Human Kinetics, Champaign, USA.
Stewart, A. L., Verboncoer, C. J., Mclellan, B. Y., Gillis, D. E., Rush, S., Mills, K. M., Ritter, P. L. \& Brown, B. W. (2001). "Physical Activity Outcomes of CHAMPS II: A Physical Activity Promotion Program for Older Adults," The Journals of Gerontology. Series A, Biological Sciences and Medical Sciences, 58 (8) M465M70.

Vandervoort, M. \& McComas, A. J. (1986). "Contractile Changes in Opposing Muscles of the Human Ankle Joint with Aging," Journal of Applied Physiology, 61 361-7.

Vitiello, M. V., Wilkinson, C. W., Merriam, G. R., Moe, K. E., Prinz, P. N., Ralph, D. D., Colasurdo, E. A. \& Schwartz, R. S. (1997). "Successful 6-Month Endurance Training Does Not Alter Insulin-Like Growth FactorI in Healthy Older Men and Women," The Journals of Gerontology. Series A, Biological Sciences and Medical Sciences, 52 (3) M149M54.

WHO. (2004). Global Strategy on Diet, Physical Activity and Health, Geneva, Switzerland, WHO, Swiss. 